\title{
Ferramentas Computacionais como Recurso Didático no Curso de Engenharia Química
}

\author{
Adriano Cancelier* \\ * Departamento de Engenharia Química, Universidade Federal de Santa Maria (UFSM), Brasil. \\ E-mail: adriano.cancelier@ufsm.br. \\ Murilo Cesar Costelli \\ •ACEA - Curso de Engenharia Química, Universidade Comunitária da Região de Chapecó \\ (UNOCHAPECO), Brasil. \\ E-mail: mccostelli@unochapeco.edu.br. \\ Adriano da Silva \\ ${ }^{`}$ Escola de Química e Alimentos, Universidade Federal do Rio Grande (FURG), Brasil \\ E-mail: adrianosilva@furg.br. \\ Toni Jefferson Lopes` \\ `Escola de Química e Alimentos, Universidade Federal do Rio Grande (FURG), Brasil. \\ E-mail: tjlopes@furg.br. \\ Iône Inês Pinsson Slongo ${ }^{\circ}$ \\ - Programa de Pós-Graduação em Educação (PPGE), Universidade Federal da Fronteira Sul, \\ Campus Chapecó (UFFS), Brasil. \\ E-mail: ione.slongo@uffs.edu.br.
}




\title{
Resumo
}

No ensino de Engenharia existe o predomínio do método tradicional, com aulas expositivas e o conhecimento centrado na figura do professor. Neste trabalho, buscou-se avaliar se o emprego de ferramentas computacionais no processo ensino/aprendizagem contribui para transformar, em parte, este antigo paradigma no ensino de Engenharia, particularmente em cursos de Engenharia Química. Como metodologia para a pesquisa utilizou-se um questionário, com questões fechadas, encaminhado via correio eletrônico (e-mail), aos professores que atuam em cursos de graduação em Engenharia Química de três instituições do Estado de Santa Catarina, Brasil. Os dados apontam que o uso de ferramentas computacionais vem crescendo, embora ainda muito focado na solução de problemas específicos. Os professores pesquisados demonstram a intencionalidade de proporcionar maior integração entre as diferentes áreas do conhecimento, o qual seria facilitado pelo uso de softwares computacionais.

Palavras-Chave: Processo ensino/aprendizagem, Recursos didáticos, Softwares computacionais.

\begin{abstract}
In engineering education, there is the predominance of the traditional teaching method with lectures and knowledge centered on the figure of the professor. In this study, we sought to assess whether the use of computational tools in the teaching/learning process contributes to transform, in part, this old paradigm in engineering education, particularly in Chemical Engineering courses. As a methodology for the research, a questionnaire with closed questions was sent via electronic mail (e-mail) to professors who work in undergraduate courses in Chemical Engineering from three institution in the State of Santa Catarina, Brazil. The data indicate that the use of computational tools is growing, although still very focused on solving specific problems. Professors surveyed demonstrate the intentionality of provide greater integration between different areas of knowledge, which would be facilitated by the use of computer software.
\end{abstract}

Keywords: Teaching/learning process, Didactic resources, Computer software.

\section{Resumen}

En la enseñanza de la ingeniería existe el predominio del método tradicional, con clases expositivas y los conocimientos centrados en la figura del profesor. Este trabajo objetivó evaluar si el uso de herramientas computacionales en el proceso de la enseñanza/aprendizaje contribuye a transformar, en parte, este antiguo paradigma en la enseñanza de la ingeniería, particularmente en el curso de Ingeniería Química. La metodología para este estudio utilizó un cuestionario con preguntas cerradas, enviados a través de correo electrónico (e-mail), a los profesores que trabajan en facultades o escuelas de Ingeniería Química de tres instituciones del Estado de Santa Catarina, Brasil. Los datos indican que el uso de herramientas computacionales está creciendo, aunque todavía muy centrado en la resolución de problemas específicos. Los profesores participantes del estudio demuestran la intención de proporcionar una mayor integración entre las diferentes áreas del conocimiento, que se ve facilitada por el uso de programas informáticos.

Palabras claves: Proceso de enseñanza/aprendizaje, Recursos de aprendizaje, programas informáticos. 


\section{Introdução}

O modelo tradicional de ensino, adotado no ensino da Engenharia na maioria das instituições de ensino do Brasil, está apoiado na transmissão de conhecimentos, que normalmente focaliza os aspectos conceituais das diversas teorias, sem a sua necessária contextualização. A reprodução desses conhecimentos é valorizada por meio do estímulo à memorização, pela prática repetitiva dos mecanismos e da lógica de funcionamento dos modelos conceituais e pela aplicação de técnicas e métodos como forma única de solução de problemas ${ }^{1}$.

Deste modelo de ensino decorrem relações entre professor, aluno e conteúdo. O professor, o centro do conhecimento, especialista da área e transmissor dos saberes que o aluno necessita se apropriar. O aluno, um ser passivo e receptor, um "recipiente" a ser preenchido com um conhecimento repassado em frações ideais (conteúdo programático) de modo a propiciar a máxima utilização de todos os recursos envolvidos, incluindo-se o tempo e espaço. É de conhecimento comum entre os profissionais do ensino de Engenharia que este modelo de ensino precisa evoluir, pois não cabe mais em uma Sociedade onde o conhecimento, principalmente em termos de conteúdo, pode ser adquirido por diferentes meios, além daquele transmitido pelo professor ${ }^{2}$.

De acordo com Belhot ${ }^{3}$, a mudança no ensino começa a ocorrer na medida em que a tecnologia permite ao aluno buscar o conhecimento sem a participação direta do professor, ou seja, a informação não precisa ser necessariamente repassada em sala de aula em uma aula expositiva. Esse atalho muda fundamentalmente a relação de ensino, o professor (instrutor) deixa de ser o único elo com o conhecimento, conforme ilustra a Figura 1.

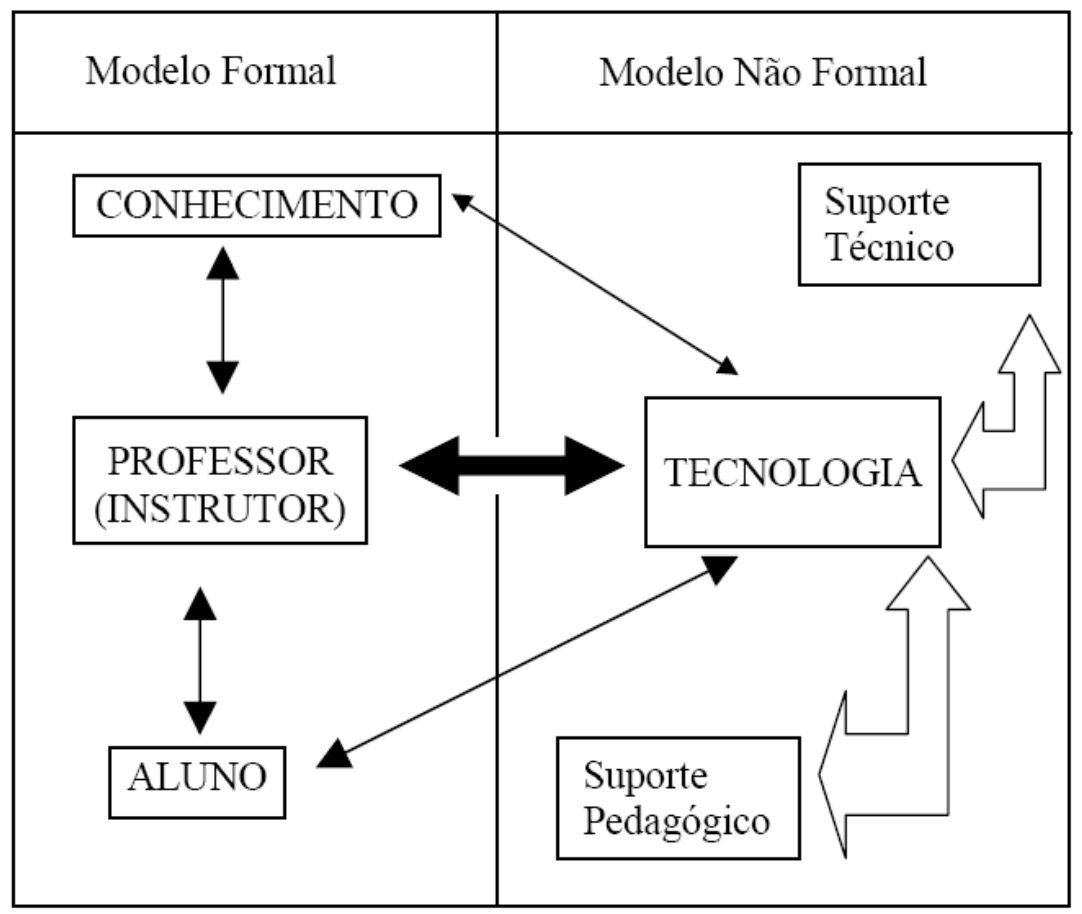

Figura 1. A Tecnologia criando acesso direto ao conhecimento. Fonte: Belthot ${ }^{3}$.

É importante ressaltar que, na perspectiva apresentada, o professor passa a ser mediador 
do conhecimento científico. Mesmo com o uso de modernas tecnologias, estas não substituirão o papel mediador desempenhado pelo professor.

De forma simplificada, pode-se observar que a Figura 1 evidencia o papel do aluno como ator do seu próprio conhecimento e que este processo pode ser facilitado com o emprego de tecnologias adequadas.

O mercado de trabalho e as indústrias passam por profundas transformações, essas mudanças exigem cada vez mais Engenheiros qualificados e atualizados. No futuro, os empregos de alta qualificação exigirão familiaridade com a tecnologia. Com a rapidez em que o mundo evolui, todos precisam se tornar aprendizes e, a formação do indivíduo deve privilegiar o desenvolvimento das competências mínimas exigidas para sua atuação profissional ${ }^{3}$.

O desenvolvimento das ferramentas computacionais possibilita a expansão de uma fronteira até então pouco explorada, a da incorporação da simulação numérica como método de ensino ${ }^{4}$. Esta metodologia possibilita a solução de problemas mais complexos, permitindo a demonstração/solução de aplicações mais próximas de um contexto físico real, sem a necessidade da incorporação de hipóteses desnecessárias ou a compartimentalização de conteúdos. Todavia, é importante destacar que o estudo torna-se mais aprofundado, pois exige também conhecimentos de informática, tanto para o docente quanto para o discente.

A modelagem matemática, em conjunto com o processo de visualização de um modelo de equipamento, propicia ao Engenheiro um melhor entendimento de um processo ou parte dele. Desta forma, a modelagem e a simulação de processos são poderosas ferramentas para o estudo e entendimento do comportamento de processos, além do seu desenvolvimento e otimização. Estas ferramentas já encontram grande aplicação no meio industrial e no campo da pesquisa, porém ainda não são muito utilizadas no meio acadêmico como um método sistematizado para o ensino.

Considerando-se estes pressupostos, o principal objetivo deste estudo foi verificar o modo como os professores avaliam a importância e viabilidade do uso de ferramentas computacionais e simulação matemática como recurso didático de disciplinas da área específica, no Curso de graduação em Engenharia Química. A partir de entrevistas com professores da área, procurou-se investigar qual a sua compreensão acerca das principais implicações do uso de ferramentas computacionais para o processo de ensino/aprendizagem, buscando revelar a importância destas para o estudo de problemas complexos e contextualizados com a profissão. Entre os professores entrevistados, também se buscou compreender quais as principais dificuldades de implantação de ferramentas computacionais como recurso didático nas aulas das disciplinas do curso de graduação em Engenharia Química.

\section{Metodologia}

Este trabalho propôs um estudo sobre a possibilidade de inserção de ferramentas computacionais como recurso didático/pedagógico no processo ensino/aprendizagem nos cursos de graduação em Engenharia Química. O estudo realizou uma pesquisa entre os professores de diferentes áreas do curso sobre a sua percepção do emprego deste recurso como meio facilitador da construção do conhecimento.

A pesquisa foi realizada com professores de Cursos de Engenharia Química de três instituições, de diferentes regiões do estado de Santa Catarina, sendo a UNOCHAPECÓ, UFSC E UNISUL. Foram aplicados questionários com questões fechadas. A pesquisa procurou analisar variáveis que abordem o processo de implantação das ferramentas computacionais como metodologia de ensino, as dificuldades encontradas, além dos benefícios obtidos. Foi possível avaliar também se o uso deste recurso didático esta sendo feito de modo estruturado e orga- 
nizado dentro dos cursos ou disciplinas, ou se a utilização é esporádica, apenas para resolver problemas em situações específicas.

O questionário foi encaminhado via e-mail aos docentes que ministraram aulas no semestre 2009/1 nas instituições citadas, abrangendo-se as diferentes áreas e períodos do curso de graduação em Engenharia Química, obtendo-se, ao todo, 22 respostas.

\section{Resultados e discussão}

A primeira questão procurou avaliar qual a área de atuação do docente, com o objetivo de evidenciar a afinidade desta com o emprego de Tecnologias de Informática. Os resultados são apresentados no Gráfico 1. Percebe-se que a maioria dos professores que participaram da pesquisa atua no ciclo profissionalizante do curso de Engenharia Química. Esta observação é mais clara quando se apresentam as respostas por núcleos disciplinares, conforme ilustra o Gráfico 2.

No Gráfico 2 pode-se constatar que mais de $80 \%$ dos conteúdos trabalhados pelos professores que participaram da pesquisa referem-se aos fundamentos técnicos específicos do trabalho profissional. É importante ressaltar que o número de professores que atuam na área profissionalizante é maior e que o questionário foi encaminhado aos professores de todas as áreas. Entretanto, não se obteve resposta de todos, principalmente das áreas sociais e básicas.

O Gráfico 3 apresenta a relação percentual dos professores que utilizam alguma ferramenta computacional como recurso didático no curso de Engenharia Química, onde fica evidente que este recurso é utilizado pela maioria dos professores entrevistados.

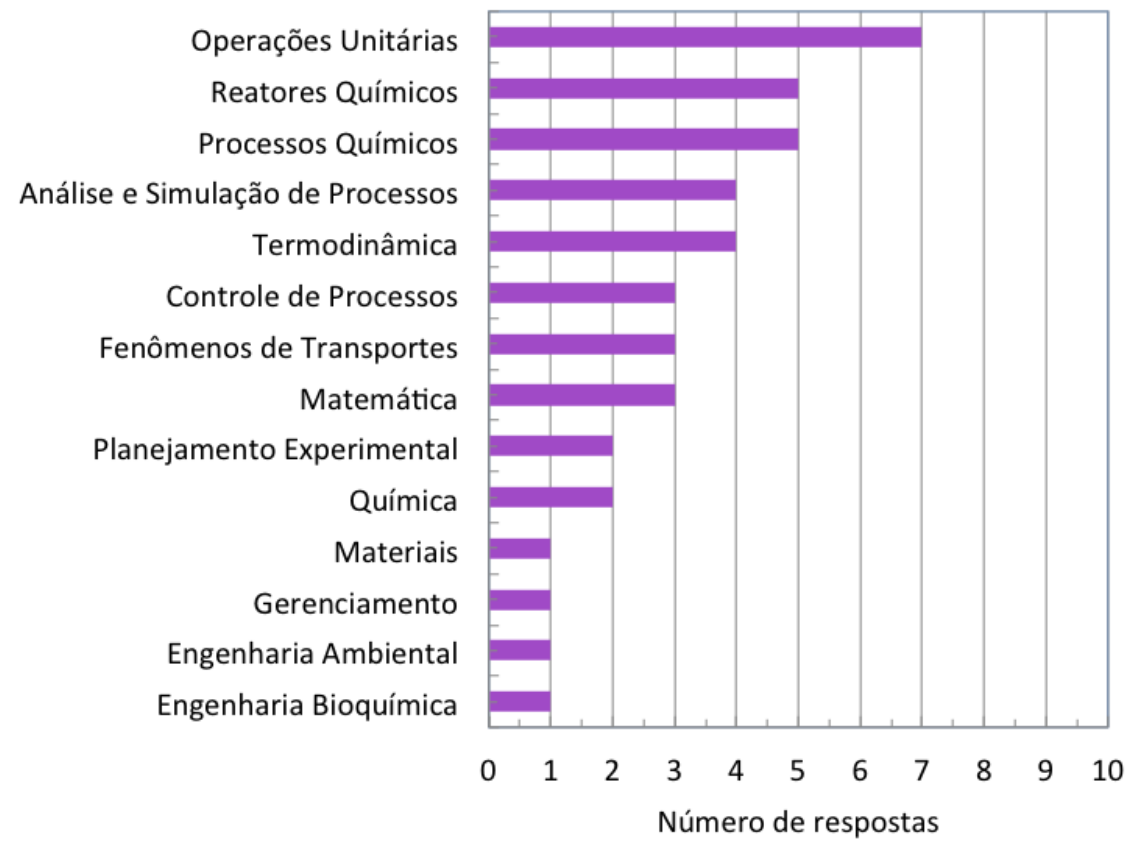

Gráfico 1. Áreas de atuação dos professores que responderam ao questionário. 


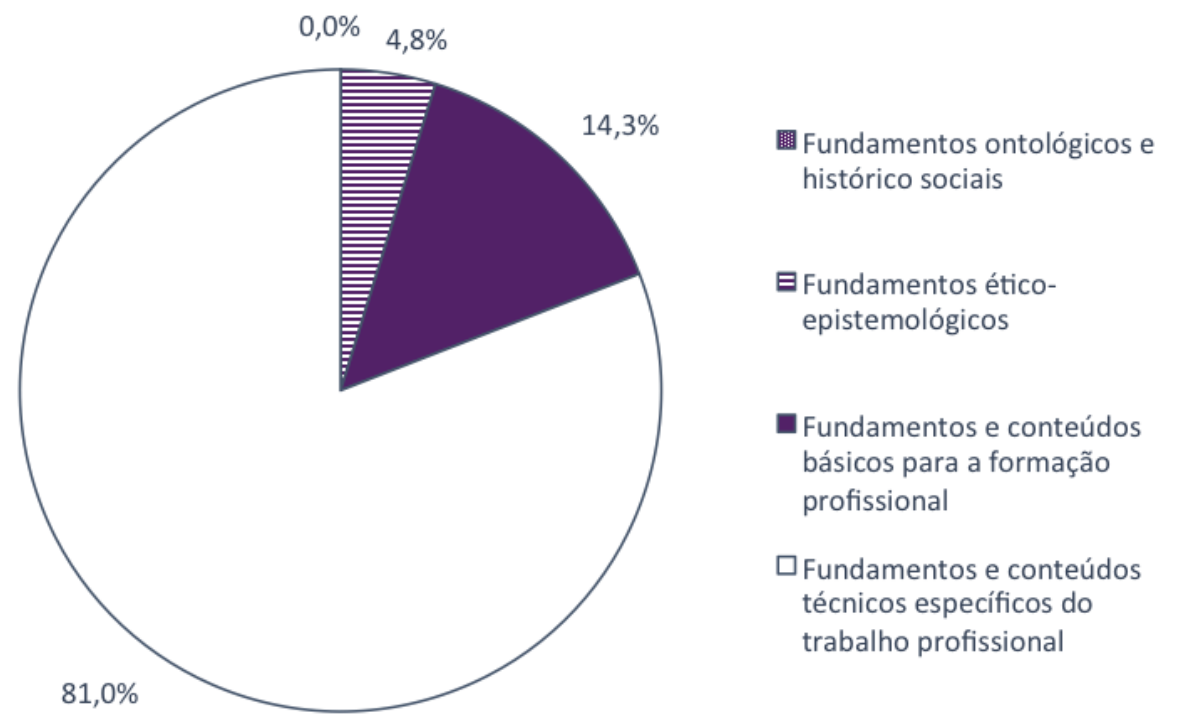

Gráfico 2. Núcleos disciplinares dos professores que responderam ao questionário.

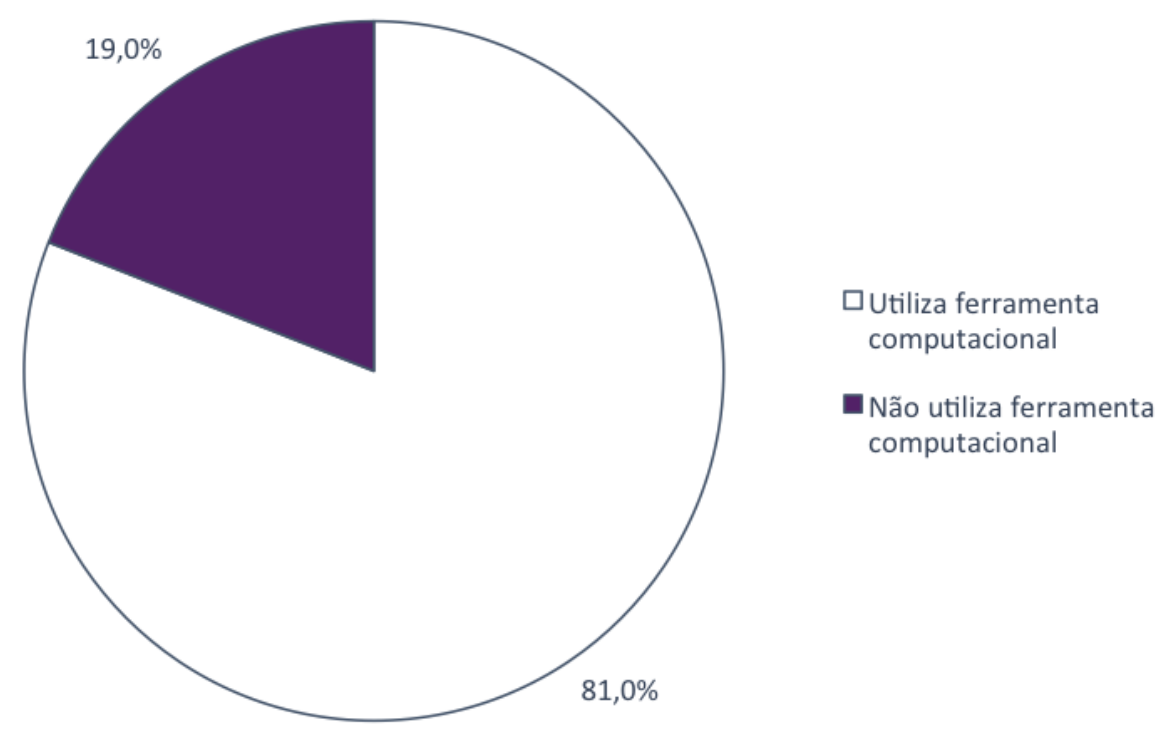

Gráfico 3. Percentual dos professores que utilizam alguma ferramenta computacional. 
Ao se relacionar este resultado com o apresentado no Gráfico 2, pode-se observar que o uso da tecnologia no ensino de Engenharia Química é mais empregado por professores que trabalham fundamentos e conteúdos técnicos específicos do trabalho profissional. Além disso, pelas respostas obtidas, verifica-se que o uso de ferramentas computacionais também é feito por alguns professores do núcleo de fundamentos e conteúdos básicos para a formação profissional, principalmente na área de Matemática. Este resultado demonstra uma tendência importante para a área, sugerindo que o "quadro-negro" possa estar perdendo a centralidade da aula universitária e que os professores estão de fato buscando recursos que colocam o aluno em ação, tirando-o da posição de mero ouvinte. Dessa forma, os professores estão buscando alternativas para modificar, ao menos em parte, a aula expositiva tradicional.

Considerando-se o grande número de professores que utilizam ferramentas computacionais, é importante averiguar quais são as mais utilizadas. O Gráfico 4 mostra esta relação, onde é possível perceber a diversidade de softwares utilizados, desde ferramentas específicas para determinadas aplicações até compiladores, onde o aluno é instigado a construir seus próprios programas para aplicações nas diferentes áreas do curso.

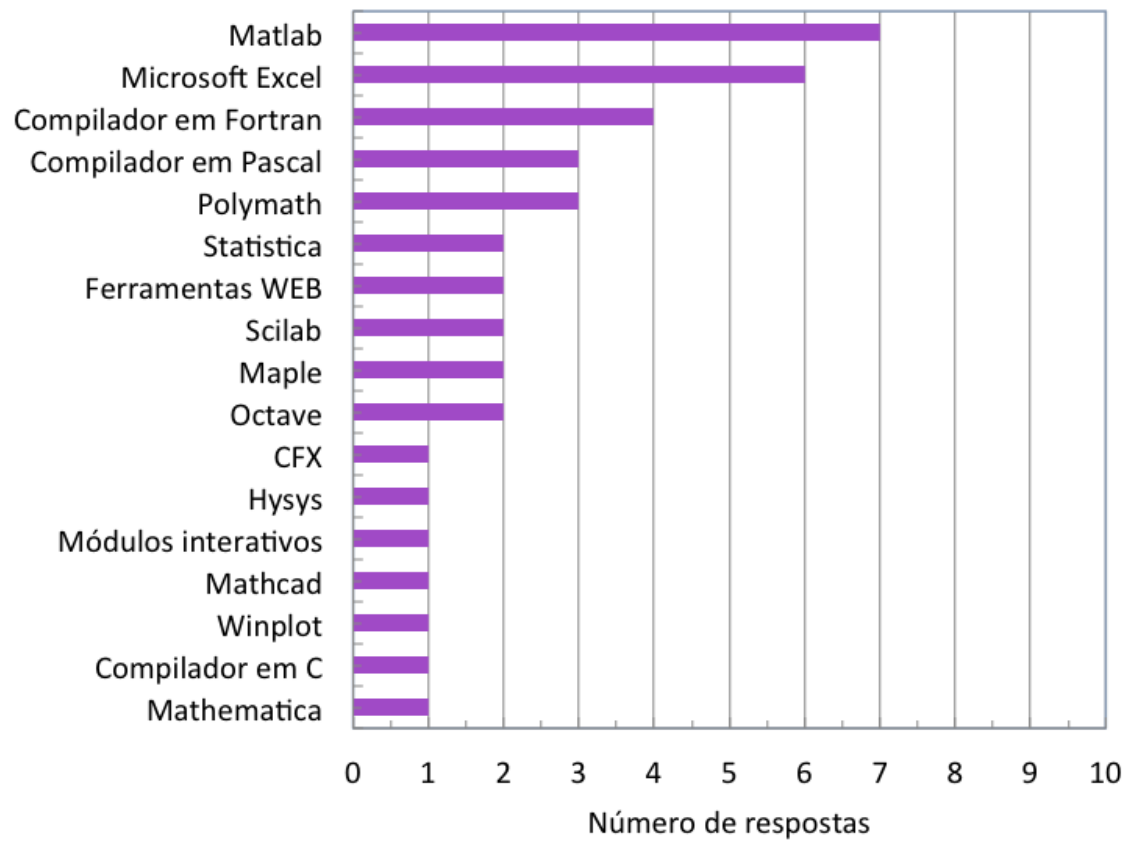

Gráfico 4. Softwares utilizados no ensino de Engenharia Química.

Observa-se que as ferramentas mais utilizadas são o Matlab, Excel, compiladores Fortran e Pascal, além do software Polymath. Analisando-se estes aplicativos, pode-se dizer que o Matlab e Excel encontram aplicabilidade desde as fases iniciais do curso. O Matlab possui uma linguagem prática, além de um grande número de ferramentas matemáticas já prontas e inclusas no próprio programa. Isso pode explicar sua utilização em diferentes áreas do curso. Na mesma linha do Matlab, porém fazendo parte da classe de softwares livres, tem-se o Octave. Apesar de distribuído gratuitamente, o mesmo apresenta menor uso, talvez pela menor divulgação. O software Microsoft Excel apresenta diversas utilidades na análise de dados experimentais de forma gráfica, além de facilitar o tratamento matemático destes 
dados como planilha de cálculo. Considerando o grande número de disciplinas práticas, que necessitam de tratamento de dados, é fácil entender sua extensa aplicação.

Como ferramentas para a construção de programas, foram citados os compiladores Fortran, Pascal (incluído o Delphi) e C, sendo os dois primeiros mais utilizados. O uso mais intenso destes pode estar associado, principalmente, pela linguagem ser mais simples e atrativa aos estudantes do curso.

O Gráfico 5 mostra as disciplinas onde são utilizadas as ferramentas computacionais no processo ensino/aprendizagem no curso de Engenharia Química.

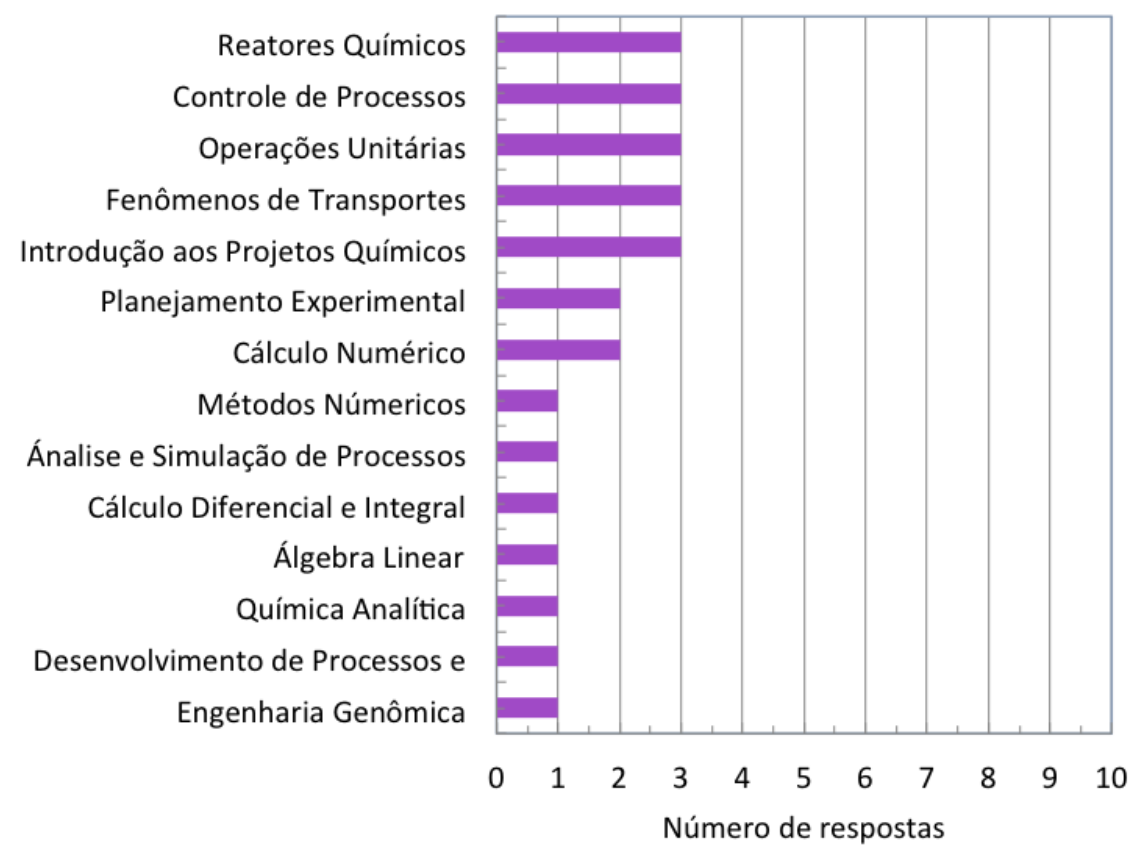

Gráfico 5. Disciplinas onde são empregadas ferramentas computacionais no processo ensino/aprendizagem.

Percebe-se que são disciplinas distribuídas nas diferentes fases do curso, tanto do núcleo de fundamentos e conteúdos básicos para a formação profissional, quando do núcleo fundamentos e conteúdos técnicos específicos do trabalho profissional. Não são citadas disciplinas do núcleo de fundamentos ontológicos e histórico sociais. Entretanto, não se pode afirmar que nestas disciplinas não se utilizem ferramentas computacionais no processo ensino/aprendizagem, pois não se obteve nenhuma resposta de professores desta área, conforme pode ser verificado no Gráfico 2.

Além da importância de averiguar se as ferramentas computacionais são utilizadas no processo de ensino/aprendizagem, também é importante conhecer qual é a frequência com que as mesmas são utilizadas, de modo a apontar se o uso deste recurso didático é pontual em função de alguma demanda específica ou, se faz parte da rotina da disciplina. Esta análise pode ser feita a partir dos dados do Gráfico 6, onde é possível perceber que aproximadamente $32 \%$ das respostas apontam que são utilizadas ferramentas computacionais em mais de $30 \%$ do conteúdo das disciplinas trabalhadas. 


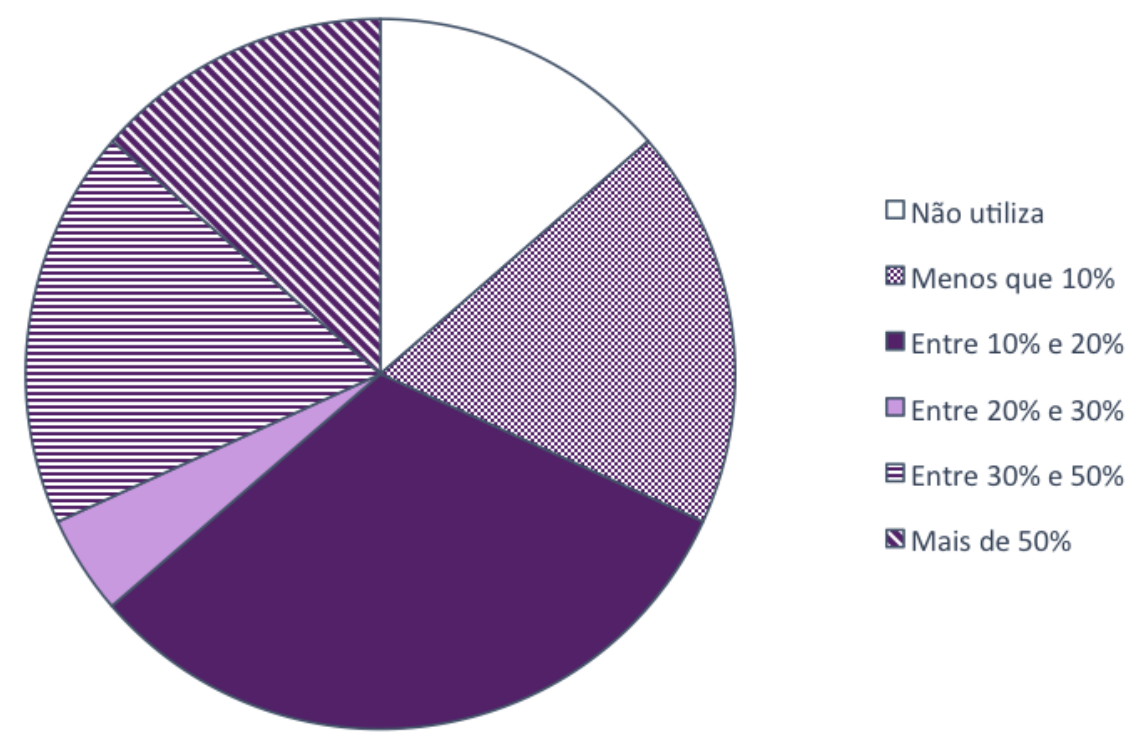

Gráfico 6. Com que frequência os docentes utilizam ferramentas computacionais em alguma disciplina no curso de graduação em Engenharia Química.

O uso de ferramentas computacionais no processo de ensino/aprendizagem no curso de graduação em Engenharia Química não é uma prática esporádica. Os dados mostram que tais recursos didáticos começam a fazer parte do cotidiano do curso e, em sua grande maioria, são utilizadas porque facilitam o processo ensino/aprendizagem, além de serem muito úteis para a resolução de aplicações específicas do campo de abrangência da área, conforme observado no Gráfico 7 . De fato, Fraga et al. ${ }^{5}$ concluem que o uso de ferramentas computacionais e simuladores estimulam o aprendizado por permitir que o aluno possa interagir mais facilmente com o conhecimento trabalhado, além de possibilitar melhor percepção visual.

Depreende-se dos dados apresentados no Gráfico 7, que os docentes não utilizam as ferramentas computacionais apenas como meio de facilitar o seu trabalho, assim como não consideram que a sua maior motivação ao ensino seja um aspecto que os levem a utilizar tal tecnologia. Este fato é evidenciado quando se avaliam as respostas do Gráfico 8. Observase que o principal motivo que leva os professores a utilizarem ferramentas computacionais como recurso didático é a possibilidade de trabalhar com problemas complexos, onde se pode aplicar, ao mesmo tempo, conhecimentos de diferentes áreas técnicas do curso, ou seja, a partir do uso de ferramentas computacionais é possível visualizar um problema de forma multidisciplinar. Este é um ponto chave para uma compreensão mais adequada das interações entre as diferentes variáveis que interferem em determinado sistema. Isso permite ao estudante de Engenharia a visualização do sistema como um todo e não apenas como parte de um "quebra-cabeças", muitas vezes, impossível de ser decifrado e remontado. Sen et al. ${ }^{6}$ também observaram que o emprego de ferramenta computacional auxilia o trabalho docente ao tratarem questões de multidisciplinaridade no curso de Engenharia da Computação. Além disso, concluíram que este recurso didático pode motivar o estudo por parte dos discentes. 


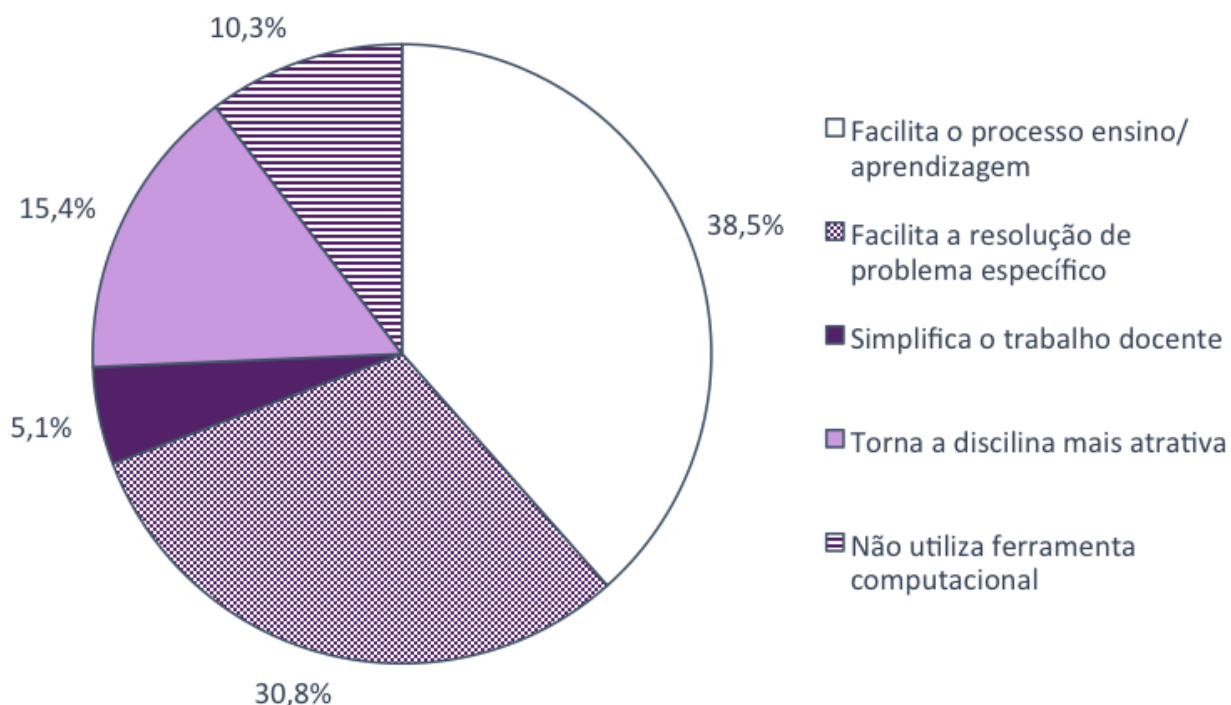

Gráfico 7. Com que propósito os docentes utilizam alguma ferramenta computacional em suas disciplinas no curso de graduação de Engenharia Química.

Esta nova maneira de construir o conhecimento sobre os processos físico-químicos tem facilitado a autonomia do estudante de Engenharia Química em concretizar seu aprendizado. Isto tem sido possível porque o que é trabalhado nas diferentes disciplinas passa a ter maior significado quando tratado de forma conjunta, em um problema real, mesmo que esta questão não tenha sido destacada no Gráfico 8.

Evidencia-se que os docentes atribuem às ferramentas computacionais um papel formativo relevante. Consideram que os estudantes ficam mais preparados para o mercado de trabalho e mais motivados na apreensão dos conhecimentos discutidos de forma teórica. $\mathrm{O}$ maior preparo ao mercado de trabalho também é uma consequência da melhor qualidade do processo ensino/aprendizagem, que passa a se preocupar também com a maneira com que o conhecimento é construído e não apenas com a quantidade de informações repassadas.

Quando se discute o papel das ferramentas computacionais no processo ensino/aprendizagem no curso de graduação em Engenharia Química, conforme é possível observar no Gráfico 9, a grande maioria dos professores que responderam ao questionário considera que estas se constituem em importantes meios para o aprendizado e consolidação de conhecimentos.

Portanto, esta análise apenas confirma o que estava sendo discutido a partir das respostas apresentadas no Gráfico 8, que buscou conhecer as principais razões que justificam o uso desta tecnologia no ensino de Engenharia.

Em relação ao tipo de ferramenta computacional, se aquela onde o aluno possa desenvolver seu próprio programa ou uma ferramenta já pronta, para um determinado tipo de aplicação, detectou-se que os professores não possuem uma preferência clara, conforme observado no Gráfico 10. 


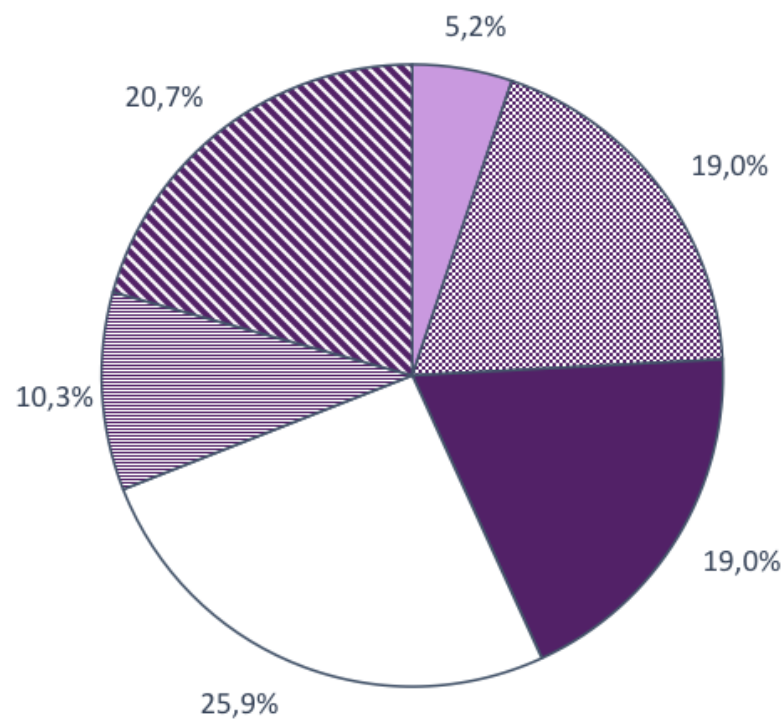

$\square$ Motivação docente no processo de ensino

Motivação discente no processo de aprendizagem

- Facilita a compreensão de processo fisicos químicos

$\square$ Colabora com a solução de problemas complexos

目 Maior autonomia ao discente na aprendizagem

N Maior preparo do discente para o mercado de trabalho

Gráfico 8. Em que aspecto os docentes consideram que o uso de ferramentas computacionais colabora no processo ensino/aprendizagem no curso de graduação de Engenharia Química.

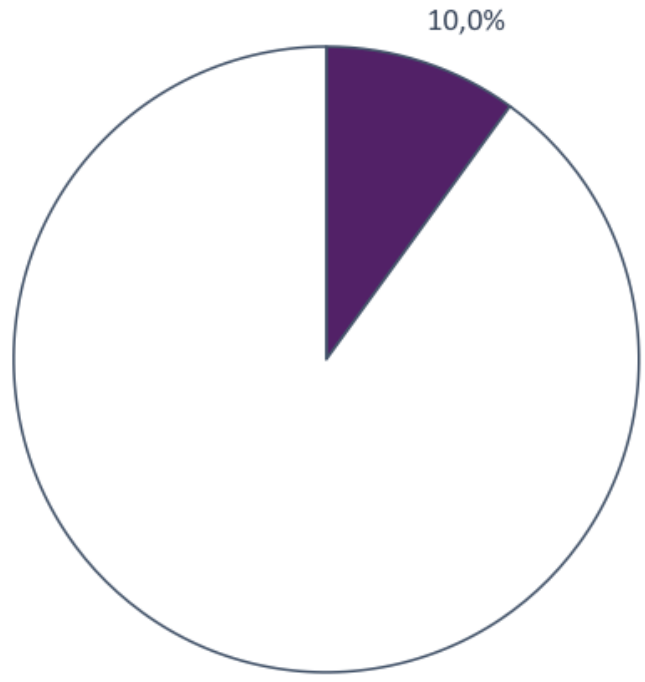

- São apenas mecanismos auxiliares na solução matemática de um problema

$\square$ Constituem-se em importantes meios para o aprendizado e consolidação de conhecimentos

$90,0 \%$

Gráfico 9. Como as ferramentas computacionais são consideradas pelos docentes no curso de graduação de Engenharia Química. 


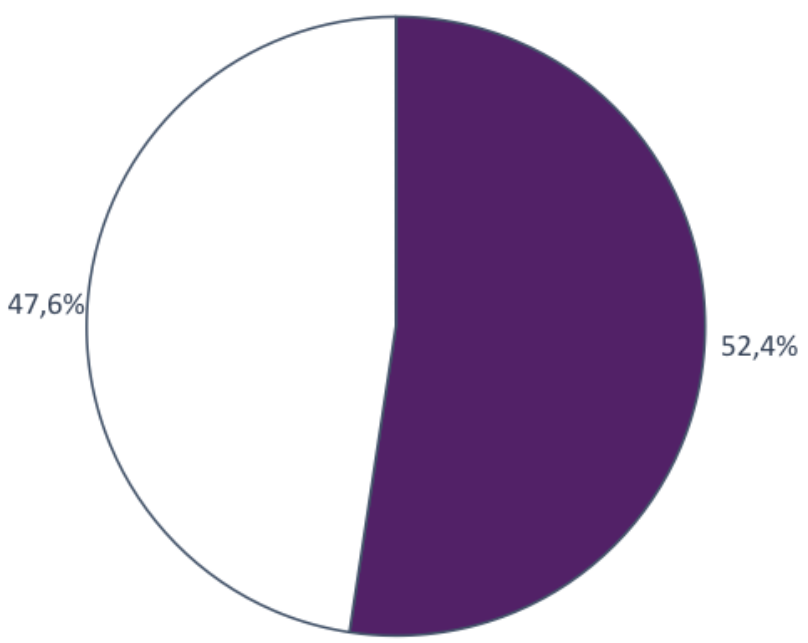

Ferramentas onde o acadêmico possa desenvolver seus próprios programas

Gerramenta computacional já pronta para um determinado problema ou tipo de aplicação

Gráfico 10. Preferência sobre os tipos de ferramentas computacionais utilizadas no processo ensino/aprendizagem no curso de graduação de Engenharia Química.

Ao analisar o padrão de respostas, pode-se considerar que as duas experiências, na visão dos professores pesquisados, são positivas e devem ser utilizadas de modo complementar. Portanto, é importante que o aluno seja capaz de construir seu próprio programa (software) computacional, mas também seja capaz de utilizar alguma ferramenta adequada para o problema que esteja estudando. Observação semelhante também foi apresentada no trabalho de Pravia et al. ${ }^{7}$, quando estudaram o uso de softwares nos cursos de Engenharia Civil, Engenharia Elétrica e Engenharia Mecânica. Foi proposto, pelos autores, que as matrizes destes cursos pudessem flexibilizar o ensino de softwares comerciais e a produção de algoritmos próprios em disciplinas optativas.

Sobre as principais habilidades desenvolvidas pelos estudantes, a partir do uso de ferramentas computacionais, destacam-se a análise crítica de problemas da área e o raciocínio lógico, conforme apontado pelos professores que responderam ao questionário, sendo os resultados apresentados no Gráfico 11.

Recebeu destaque, também, a possibilidade de integração de diferentes campos do conhecimento e a criatividade. Quando se questiona sobre os requisitos de um bom profissional na área de Engenharia, certamente estes quatro são destacados, conforme apresenta o trabalho de Silveira ${ }^{2}$. Assim, pode-se afirmar que o uso de ferramentas computacionais no processo ensino/aprendizagem de um Curso de Engenharia potencializa o desenvolvimento de habilidades inerentes à sua atuação profissional.

Belhot et al. ${ }^{4}$ discutiam que, inicialmente, nos Cursos de Engenharia, técnicas computacionais como a modelagem e simulação foram desenvolvidas como ferramentas para lidar com situações passíveis de estruturação Matemática com forte tendência para a previsão e otimização, compatível com o modelo mental e valores da época. Atualmente, a aplicação 
de simulação e modelagem visa a dar suporte ao desenvolvimento da visão sistêmica, da prática de pensar estrategicamente, da capacidade de trabalhar em equipe, de compartilhar conhecimentos e de aprender em grupo. Nesse contexto, a modelagem pode ser explorada, no mínimo, de três maneiras, segundo os autores: (1) como um processo de mapeamento cognitivo que captura o conhecimento e estimula a aprendizagem; (2) como um meio propício à experimentação e; (3) como uma forma de aprender a lidar com conflito de interesses.

Apesar do consenso entre os docentes, de que uso de ferramentas computacionais desenvolve uma séria de habilidades importantes para a atuação profissional, também existe um consenso de que ainda são necessárias aulas práticas em laboratório, conforme pode ser conferido no Gráfico 12.

Ao se analisar o padrão de resposta, há que se considerar o perfil requerido para o profissional em Engenharia Química. Este profissional atua, muitas vezes, diretamente no desenvolvimento de pesquisas em processos e produtos, controle de qualidade, instalação de equipamentos, dentre outros, ou seja, áreas que necessitam de habilidades práticas de campo, as quais não são desenvolvidas por qualquer ferramenta computacional.

O Gráfico 13 mostra as principais dificuldades apontadas pelos professores para utilizar as ferramentas computacionais no processo ensino/aprendizagem no curso de graduação em Engenharia Química.

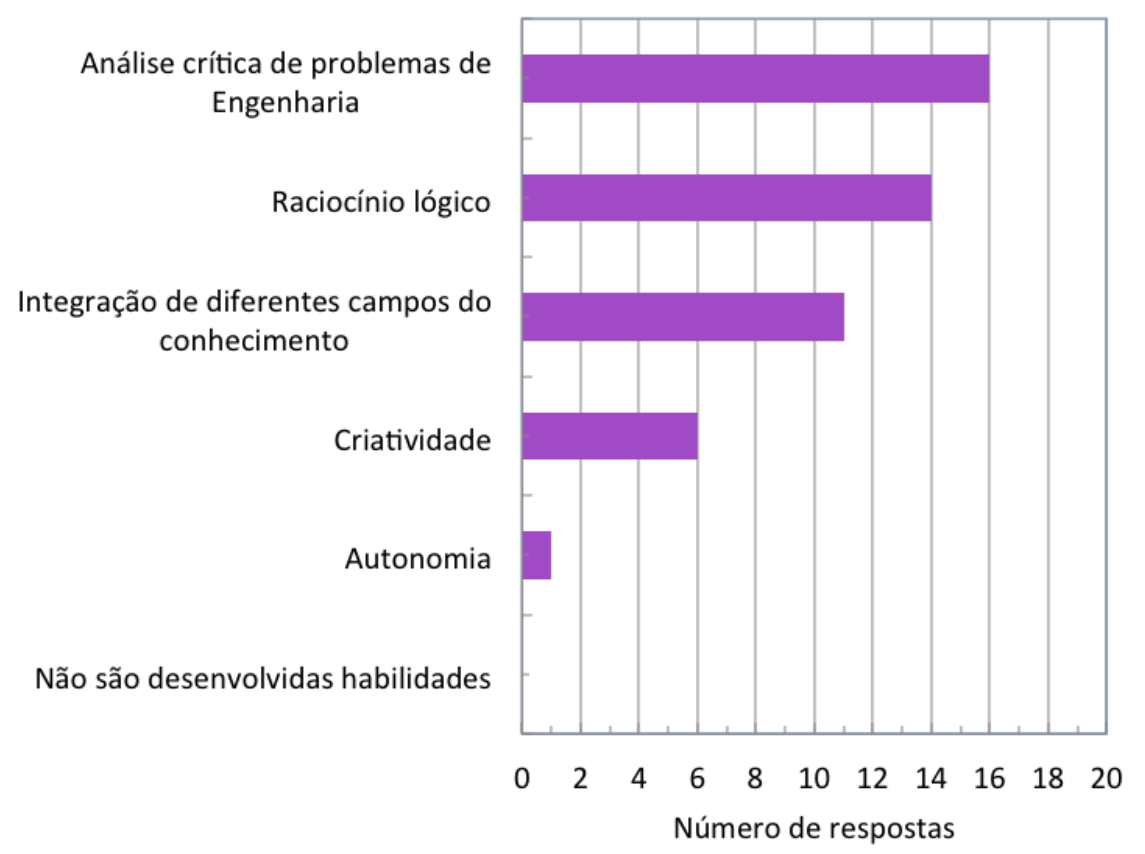

Gráfico 11. As habilidades que os docentes consideram serem mais bem desenvolvidas pelo uso de alguma ferramenta computacional. 


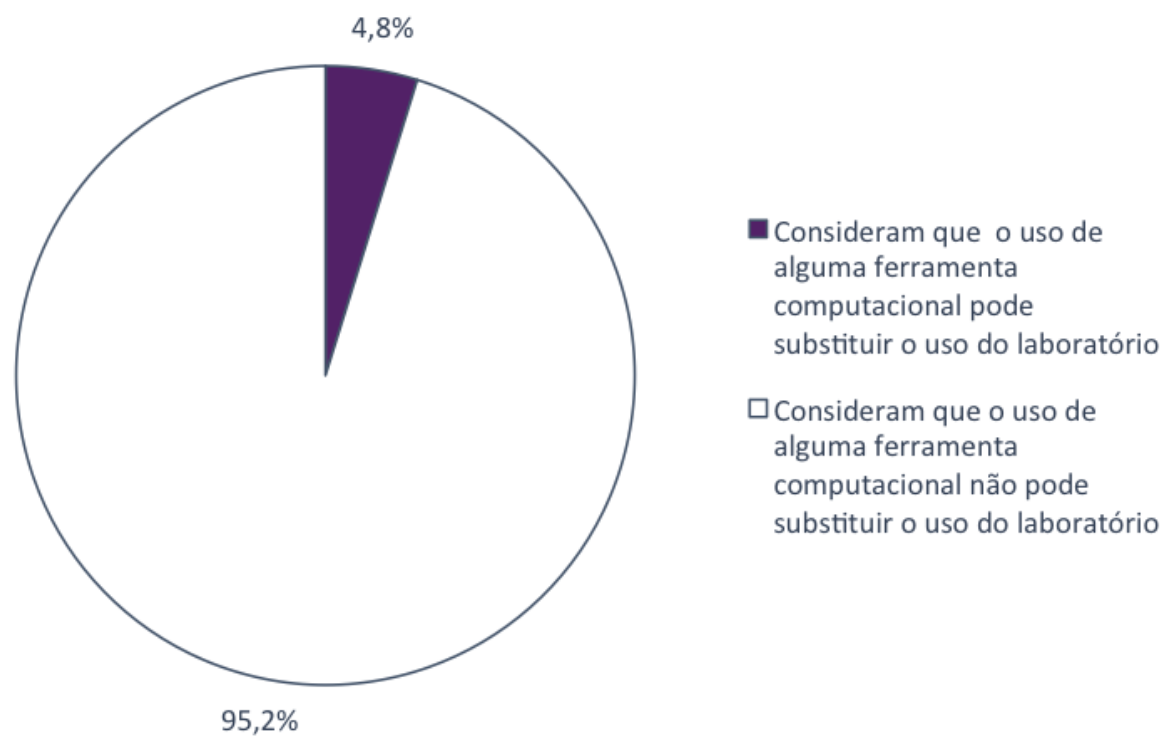

Gráfico 12. Percentual de docentes que consideram que o uso de ferramentas computacionais possa substituir o uso de laboratório.

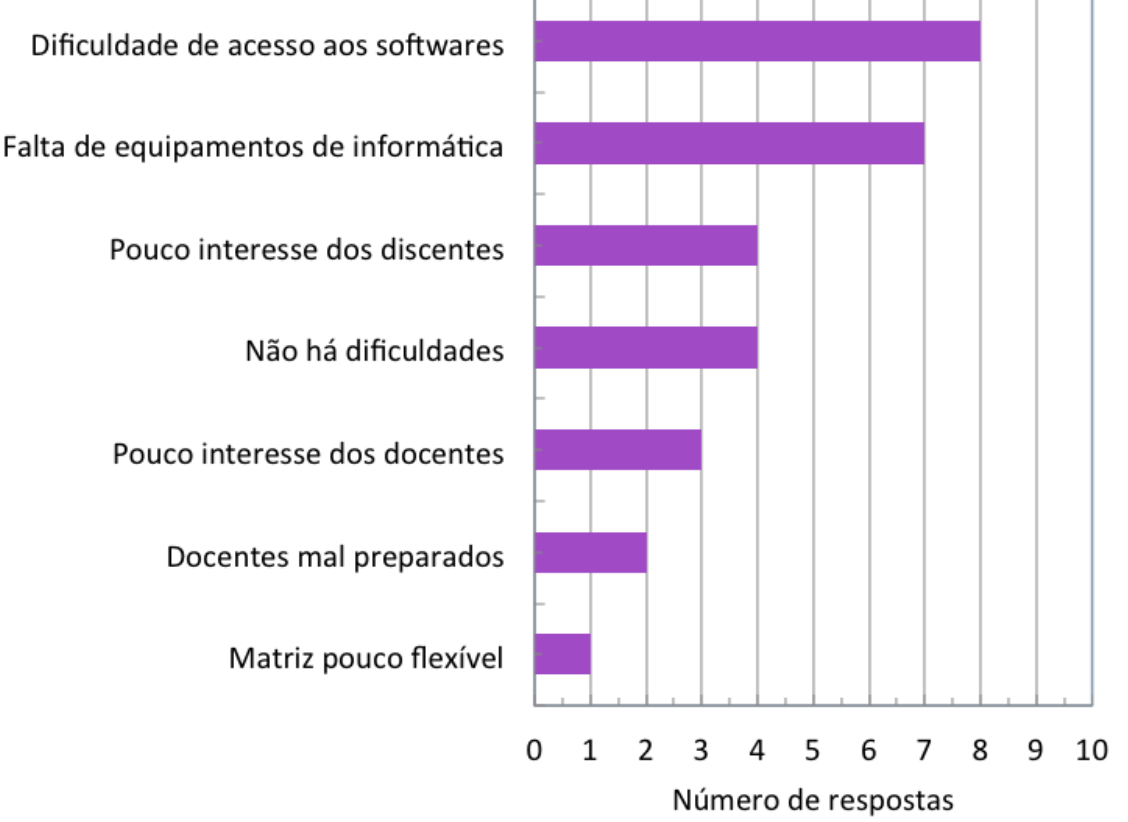

Gráfico 13. Principais dificuldades encontradas para utilizar as ferramentas computacionais no processo ensino/aprendizagem no curso de graduação em Engenharia Química. 
Dentre as apresentadas, receberam destaque duas que possuem relação com a infraestrutura e com o acesso às ferramentas. No primeiro caso, o problema apontado foi o número insuficiente de equipamentos de informática, ou de laboratórios de informática, para que as aulas possam ser ministradas. Sobre esta questão, é importante ressaltar que a maioria das respostas refere-se aos docentes que atuam em Universidade pública. Aqui há um ponto contraditório. Ao mesmo tempo em que o acesso aos softwares é mais simples neste tipo de Universidade, se tem muitos alunos para poucos laboratórios ou equipamentos de informática. Já, para as instituições que utilizam mensalidades de alunos para sua sustentabilidade, o maior problema apontado foi a dificuldade de acesso aos softwares adequados, mas não haveria problemas de falta de equipamentos ou de laboratórios de informática.

O pouco interesse dos discentes em utilizar esta tecnologia também foi apontado. Entretanto, muitas vezes, a falta de interesse do discente é motivada pelo pouco preparo do docente em apresentá-la e utilizá-la de forma adequada. Também, pode-se citar pouco preparo do docente em conseguir integrar diferentes áreas para a elaboração de problemas mais atrativos aos alunos, mostrando maior ligação com a realidade e também a necessidade de uso de tal tecnologia.

Portanto, a partir das evidências apresentadas, percebe-se a importância da formação permanente dos professores da Educação Superior, principalmente da necessidade de atualização de sua prática didático/pedagógica. Esta atualização do professor é fundamental para que em sua prática cotidiana sejam incluídos novos recursos didáticos, porém, não apenas como mero formalismo ou modismo, mas sim buscando maior interatividade com os alunos, além da possibilidade de desenvolver em conjunto habilidades essenciais para o enfrentamento de novos e constantes desafios.

Outra importante análise que pode ser feita a partir das respostas, está relacionada com as matrizes curriculares. De forma geral, os professores consideram não ser a matriz um impedimento ao uso das ferramentas computacionais, ou seja, seria possível maior integração disciplinar para a construção de conhecimentos mais sólidos a partir do uso das tecnologias disponíveis, sem a necessidade de reconstruir o projeto do curso.

\section{Conclusões}

A grande maioria dos docentes investigados considera que o emprego das ferramentas computacionais constitui-se em um importante recurso didático para facilitar e desenvolver o processo de ensino/aprendizagem e não como apenas ferramentas para a solução pontual de algum problema específico. O ideal é que ocorra maior integração entre as disciplinas da matriz curricular, para que, a partir da aplicação destas ferramentas, seja possível trabalhar problemas reais e com maior sentido ao conceito de multidisciplinaridade.

É consenso entre os professores de Engenharia entrevistados que o uso de ferramentas computacionais é um importante meio para o processo ensino/aprendizagem, as quais podem trazer maior significado aos conteúdos teóricos tratados em aula, bem como serem úteis na resolução de problemas complexos.

A incorporação das ferramentas computacionais como recurso didático não é vista como possibilidade de substituição de aulas práticas em laboratório. Além disso, a própria construção de modelos matemáticos confiáveis, para serem simulados em computador, deve ser comprovada experimentalmente, ou seja, a atividade de laboratório continuará com a mesma importância.

O estudante de Engenharia deve ser instigado no sentido de criar e adaptar modelos existentes, especificando variáveis e desenvolvendo relações entre elas a partir da investigação 
de como essas variáveis podem estar relacionadas.

Dentre as respostas obtidas, foi possível avaliar que o uso de ferramentas computacionais no ensino de Engenharia é importante tanto para disciplinas no núcleo de conhecimentos básicos, quanto para disciplinas do núcleo de conhecimentos específicos para a atuação profissional.

As maiores dificuldades apontadas para o uso mais intensivo das ferramentas computacionais no ensino de Engenharia são a infraestrutura de laboratórios de informática e a dificuldade de aquisição dos softwares necessários. Também se detectou que existe certa dificuldade dos professores para a incorporação desta tecnologia no cotidiano de suas disciplinas, assim como de os mesmos trabalharem de forma multidisciplinar, justificando ainda mais a necessidade das ferramentas.

O desenvolvimento de uma série de habilidades também pode ser potencializado pelo uso das ferramentas computacionais na visão dos professores. Entre as habilidades, destacam-se a análise crítica, raciocínio lógico e criatividade.

É evidente e urgente a qualificação dos professores de Engenharia para o uso das novas ferramentas tecnológicas disponíveis, facilitando assim a construção e o acesso ao conhecimento, além de tornar a aprendizagem mais significativa.

\section{Referências}

1. BAZZO, W. A. Ciência, Tecnologia e Sociedade e o Contexto da Educação Tecnológica. Florianópolis: Editora UFSC, 1998.

2. SILVEIRA, M. A. da. A formação do engenheiro inovador : uma visão internacional. Rio de Janeiro: Editora PUC-RIO, 2005.

3. BELHOT, R. V. A Didática no Ensino de Engenharia In: CONGRESSO BRASILEIRO DE ENSINO DE ENGENHARIA, 33., 2005, Campina Grande. Anais...Campina Grande, 2005. CD-ROM.

4. BELHOT, R. V.; MALAVÉ, C.O.; FIGUEIREDO, R. S. Uso da Simulação no Ensino de Engenharia In: CONGRESSO BRASILEIRO DE ENSINO DE ENGENHARIA, 29., 2001, Porto Alegre. Anais... Porto Alegre, 2001. CD-ROM.

5. FRAGA, J. R. C. P.; CAStro, M. C.; AlveS, A.; FERRAZ, K. Metodologia de Ensino Baseada no Levantamento do Perfil dos Alunos Aliado ao Uso de Recursos Computacionais. In: CONGRESSO BRASILEIRO DE ENSINO DE ENGENHARIA, 33., 2005, Campina Grande. Anais...Campina Grande, 2005. CD-ROM.

6. SEN, T. K.; SILVEIRA, M. S. C.; MORAIS, L. M.; SIQUEIRA, W. G. Linguagem Java Auxilia Metodologia do Ensino de Fenômenos de Transporte. In: CONGRESSO BRASILEIRO DE ENSINO DE ENGENHARIA, 33., 2005, Campina Grande. Anais...Campina Grande, 2005. CD-ROM.

7. PRAVIA, Z. M. C.; DREHMER, G. A.; SOUZA, J. P. Computação na Engenharia: Ensinar a Programar e/ou Usar Software Comercial?. In: CONGRESSO BRASILEIRO DE ENSINO DE ENGENHARIA, 33., 2005, Campina Grande. Anais...Campina Grande, 2005. CD-ROM. 